\title{
Management of severe crush injury in a front-line tent ICU after 2008 Wenchuan earthquake in China: an experience with 32 cases
} Wenfang Li ${ }^{1}$, Jun Qian², Xuefen Liu ${ }^{1}$, Qiang Zhang ${ }^{1}$, Lv Wang ${ }^{1}$, Dechang Chen ${ }^{1}$ and Zhaofen Lin ${ }^{1}$

\author{
${ }^{1}$ Emergency Department, Changzheng Hospital, Second Military Medical University, No. 415 Fengyang Road, Shanghai 200003, China \\ 2Intensive Care Unit, The People's Hospital of Jiangyou, No. 346 middle Jinlun Road, Jiangyou City, Sichuan Province, 621700, China \\ Corresponding author: Zhaofen Lin, linzhaofen2009@yahoo.com.cn
}

Received: 22 Mar 2009 Revisions requested: 6 May 2009 Revisions received: 4 Oct 2009 Accepted: 6 Nov 2009 Published: 6 Nov 2009

Critical Care 2009, 13:R178 (doi:10.1186/cc8160)

This article is online at: http://ccforum.com/content/13/6/R178

(C) 2009 Li et al.; licensee BioMed Central Ltd.

This is an open access article distributed under the terms of the Creative Commons Attribution License (http://creativecommons.org/licenses/by/2.0), which permits unrestricted use, distribution, and reproduction in any medium, provided the original work is properly cited.

\begin{abstract}
Introduction The experience on management of crush injury after a devastating earthquake is lacking, and there are even less reports on the front-line critical care of these patients. A frontline intensive care unit (ICU) was set up in a tent after the disastrous Wenchuan earthquake (May, 12, 2008, China), where 32 patients suffering from crush injury were treated from May 12 to May 26. This study summarized our experience on management of 32 crush injury patients in a front-line tent ICU.

Methods We retrospectively analyzed the clinical data of 32 crush injury patients treated in our frontline tent ICU. Using limited equipment, we observed the arterial blood gas parameters, blood routine, alanine aminotransferase, lactate dehydrogenase, creatine kinase, creatinine, blood urea nitrogen, and urine protein of patients. We also closely watched for changes in crush injury symptoms, urine output, and the dangerous complications of crush injury.

Results Eighteen of the 32 patients developed traumatic shock, 9 had acute renal failure, 6 had acute heart failure, 2 had stress ulcers and 4 had multiple organ dysfunction syndrome (MODS).

The symptoms of 17 patients met the criteria of crush syndrome; hemodialysis and prompt surgical intervention were given to them when necessary. Prompt treatment in our tent ICU improved the symptoms of patients to different degrees. The limb distension and sensory dysfunction were improved and the urine output was increased or even restored to the normal level in some patients. Serological parameters were improved in most patients after admission. Five (15.63\%) patients underwent amputation due to severe infection in our group. Six $(18.75 \%)$ patients died, 4 due to MODS and 2 due to acute renal failure.

Conclusions Severe crushing injuries and life-threatening complications are major causes of death after major disasters like earthquakes. Prompt treatment and close monitoring of the severe complications are of great importance in saving patients' lives. Establishment of a well-equipped front-line ICU close to the epicentre of the earthquake allows for prompt on the spot rescue of critical patients with crush injury, greatly decreasing the mortality rate and complications and avoiding amputation. There should be sufficient equipment to meet the needs of more patients.
\end{abstract}

\section{Introduction}

Disasters such as earthquake, debris flow and landslide can cause mass casualties. In addition to direct injuries to vital organs, such as the head and heart and rupture of large vessels, crush injuries caused by prolonged pressing of the body by collapsed buildings are also major causes of death. The acute increase of muscle pressure can lead to compartment syndrome, clinically manifested as progressive swelling of the involved limbs, great pain, diminishing sensory abilities and muscle strength, and even paralysis [1-3]. When exacerbated swelling of body parts, acute renal failure (ARF), shock, or hyperpotassemia is developed, crush syndrome is due to occur. The incidence of crush syndrome is $2 \%$ to $15 \%$ in all trauma patients, and it can be as high as 30\% in earthquake victims. The symptoms of crush syndrome can last for three to five days in mild cases and for one to two weeks in severe cases. About half of the victims develop ARF and the number is almost $100 \%$ in those whose symptoms last for 40 hours; among the latter about $50 \%$ need hemodialysis. The mortality of patients with crush syndrome can be as high as $40 \%$ if the condition lasts for over three weeks [4-8] 
The intensive care unit (ICU) is a setting equipped with specially trained medical professionals as well as advanced monitoring system and first aid materials. The aim of an ICU is to monitor and treat patients with critical conditions such as multiple injuries, severe infections, shock of various origins, acute organ failure and disorders of the internal environment of patients. Intensive care reflects the administration proficiency and medical technology advancement of hospitals [9-11]. Close monitoring of pediatric patients [12], aged patients [13] and patients with unstable vital signs can greatly improve their survival rate [14-16]. ICU plays an unreplaceble role in saving the lives of victims after major disasters such as earthquakes, especially those with crush syndrome and complications [1719]. Demirkiran and colleagues considered that immediate intensive care is vital to the survival of patients with crush injury and compartment syndrome [20]

On 12 May, 2008, a catastrophic earthquake measuring 8.0 on the Richter scale struck the Wenchuan region of Sichuan province, China, causing about 90,000 deaths and even more injuries. The rescue efforts were greatly hampered by the mountainous terrain and damaged roads. Many victims developed critical crush injury and compartment syndrome after their limbs were pressed for a long time during entrapment. Our group, as part of the rescue team of the Second Military Medical University, was sent to Jiangyou city, a severely hit area labouring the most severely struck Beichuan Area. A field hospital was set up in the People's Hospital of Jiangyou, which had been severely damaged during the earthquake. We rescued some undamaged equipment from the severely damaged ICU building and established a front-line tent ICU. From 12 to 26 May, 32 patients with crush injury were treated in our front-line tent ICU. In this paper we reported the treatments and outcomes of the 32 patients and summarize our experience in the front-line tent ICU.

\section{Materials and methods}

\section{Establishment of the front-line tent ICU}

Using the undamaged equipment rescued from the collapsing hospital buildings of the People's Hospital of Jiangyou, we established a front-line tent ICU, as a unit of the field hospital set up by the rescue team of the Second Military Medical University. The ICU had four beds, each equipped with a monitor (DASH3000, GE Company, Connecticut, USA), manual respirator (LVT1000, Newport Corporation, Minnesota, USA) and suction apparatus (YB. DX23D, Shanghai Medicals Corportion, Shanghai, China). Other equipments included a blood filtrum (Prisma Machinegambro, Lund, Swede), a blood gas analyzer (GEMPremier3000, Hartwell, Georgia, USA), a biochemistry inspectoscope (CELLDYN3700, Abbott diagnostics division, Chicago, Illinois, USA), a defibrillator (HEARTSTART XL, PHILIPS, Boblingen, Germany) a trachea cannula and breathing sacculus (GaleMed MR-100, Shanghai Medicals Corportion, Shanghai, China), as well as routine emergency drugs.

\section{General information of patients}

From 12 to 26 May, a total of 32 patients were admitted to our front-line tent ICU, including 21 males and 11 females, with a mean age of $45 \pm 19$ years (range 13 to 56 ). Physical examinations upon admission were: the mean body temperature, $37.2 \pm 0.6^{\circ} \mathrm{C}$ (range 36.3 to 37.6 ); the mean heart rate, 115.3 \pm 25.6 beats/min (range 85 to 142 ); mean respiratory rate, $26.9 \pm 5.7$ breaths/min (range 21 to 38 ); mean systolic blood pressure, $121.7 \pm 21.3 \mathrm{mmHg}$ (range 78 to 153 ), and mean diastolic blood pressure, $59.4 \pm 16.8 \mathrm{mmHg}$ (range 42 to 96 ).

\section{Injuries of patients}

Twenty-seven of the 32 patients had multiple injuries and five had lower limb injuries. Nine patients had unilateral lower extremity trauma and 13 had bilateral ones. Three patients had single femoral fractures and seven had bilateral femoral fractures. Thirteen patients were complicated by pelvic fractures, 11 had chest trauma, 8 had cerebral trauma, 6 had splenic rupture, 5 had open tibia fracture, 5 had spinal injuries, and 3 had perinephrium and retroperitoneal hematoma. The mean entrapment period of the patients was $3 \mid \pm 12$ hours, ranging from 2 to 121 hours. All the patients had swelling and distension of extremities, various degrees of dysesthesia and dyscinesia. Twenty-three patients had soy sauce urine (indicating hemoglobinuria). Seven suffered from anuria and six from pink foam phlegm (a symptom of acute pulmonary edema). The clinical details of the 32 patients are given in Table 1. Informed consents were obtained from each patient or their guardians, and ethical approval was obtained from the Medical Ethics Committee of Changzheng Hospital, the Second Military Medical University.

\section{Laboratory tests}

Due to the limited equipments, the parameters we could obtain included partial pressure of arterial oxygen, partial pressure of carbon dioxide, $\mathrm{PH}$ value, and base excess. Other parameters included blood cell count, serum alanine transaminase (ALT), serum lactate dehydrogenase (LDH), serum creatine kinase (CK), serum creatinine, serum urea nitrogen (BUN), and urine protein. Upon admission the blood test showed the following results:blood hematocrit $39.6 \pm 13.4 \%$ (range 23 to 52 ), leukocytes $21,562 \pm 8765 \mathrm{cells} / \mu \mathrm{L}$ (range 12,300 to 32,500 ), platelets $136,775 \pm 56,745 \mathrm{cells} / \mu \mathrm{L}$ (range 400,000 to 240,000 ).

\section{Diagnosis and treatment of patients with crush syndrome}

Crush syndrome is systemic manifestations characterized by swelling and distension of limbs, dyscinesia, myoglobinuria, and hyperpotassemia, usually caused by prolonged pressing of body parts. The mortality rate of patients with crush syndrome could be as high as $50 \%$ to $70 \%$. Crush syndrome can be diagnosed when a crush injury patient develops systemic manifestations such as shock, acidosis, and ARF [21-23]. 
Table 1

Clinical details of the 32 patients in our group

\begin{tabular}{|c|c|c|c|c|c|c|}
\hline $\begin{array}{l}\text { Patient } \\
\text { Number }\end{array}$ & Primary injury & Admitting time & Dark urine & Urine volume $(\mathrm{ml})$ & $\begin{array}{l}\text { Protei- } \\
\text { nuria }\end{array}$ & Entrapment time \\
\hline 1 & $\begin{array}{l}\text { Chest trauma, left humerus fracture and right } \\
\text { radius fracture }\end{array}$ & 13 May 2008 & $\sqrt{ }$ & 150 & ++ & 3.5 \\
\hline 2 & Brain trauma and left femur fracture & 13 May 2008 & $\sqrt{ }$ & 350 & +++ & 3 \\
\hline 3 & $\begin{array}{l}\text { Fracture of shaft of right femur, pelvic fracture, and } \\
\text { splenic rupture }\end{array}$ & 13 May 2008 & $\sqrt{ }$ & 70 & ++++ & 5 \\
\hline 4 & $\begin{array}{l}\text { Brain trauma, pelvis fracture, fracture of hypomere } \\
\text { of left femur, and right fibula fracture }\end{array}$ & 13 May 2008 & $\sqrt{ }$ & 470 & $34 U Y$ & 6 \\
\hline 5 & $\begin{array}{l}\text { Chest trauma, left humeral fracture, right ulna } \\
\text { fracture, splenic rupture }\end{array}$ & 13 May 2008 & & 630 & ++ & 2.5 \\
\hline 6 & $\begin{array}{l}\text { Left shaft of femur fracture and left tibiofibula } \\
\text { fracture }\end{array}$ & 13 May 2008 & & 560 & ++ & 4 \\
\hline 7 & Right femur fracture & 13 May 2008 & $\sqrt{ }$ & 480 & ++ & 3 \\
\hline 8 & $\begin{array}{l}\text { Brain trauma, pelvic fracture, left femoral neck } \\
\text { fracture, and right sprained knee }\end{array}$ & 13 May 2008 & $\sqrt{ }$ & 540 & ++ & 4.5 \\
\hline 9 & $\begin{array}{l}\text { Chest trauma, fracture of shaft of left humerus, } \\
\text { right ulna and radius fractures }\end{array}$ & 13 May 2008 & $\sqrt{ }$ & 560 & ++ & 2.5 \\
\hline 10 & $\begin{array}{l}\text { Brain trauma, hemopneumothorax, left shoulder } \\
\text { blade fracture, and sprain of left shoulder joint }\end{array}$ & 13 May 2008 & & 750 & ++ & 2 \\
\hline 11 & $\begin{array}{l}\text { Epimere fracture of right shin and sprain of right } \\
\text { knee }\end{array}$ & 13 May 2008 & $\sqrt{ }$ & 630 & ++ & 3 \\
\hline 12 & $\begin{array}{l}\text { Pelvic fracture, compression fracture of lumber } \\
\text { vertebral body, splenic rupture, retroperitoneal } \\
\text { hematoma, and left femoral neck fracture }\end{array}$ & 13 May 2008 & $\sqrt{ }$ & 40 & ++++ & 5 \\
\hline 13 & Chest trauma and fractures of shaft of left humerus & 13 May 2008 & $\sqrt{ }$ & 450 & ++ & 4 \\
\hline 14 & $\begin{array}{l}\text { Pelvic fracture, splenic rupture, perirenal } \\
\text { hematoma, fracture of shaft of left femur, and right } \\
\text { tibial plateau fracture }\end{array}$ & 13 May 2008 & $\sqrt{ }$ & 90 & +++ & 3.5 \\
\hline 15 & $\begin{array}{l}\text { Brain trauma, splenic rupture, fracture of right } \\
\text { shoulder blade, right shoulder joint sprain }\end{array}$ & 13 May 2008 & & 870 & ++ & 2 \\
\hline 16 & $\begin{array}{l}\text { Left tibiofibula fractures, compression fractures of } \\
\text { lumber vertebral body, and retroperitoneal } \\
\text { hematoma }\end{array}$ & 13 May 2008 & $\sqrt{ }$ & 430 & ++ & 4 \\
\hline 17 & $\begin{array}{l}\text { Pelvic fracture, fracture of shaft of right femur, and } \\
\text { left tibial fracture }\end{array}$ & 13 May 2008 & & 740 & ++ & 5.5 \\
\hline 18 & $\begin{array}{l}\text { Chest trauma, and fracture of shaft of left humerus, } \\
\text { and right clavicular fracture }\end{array}$ & 13 May 2008 & $\sqrt{ }$ & 510 & ++ & 7 \\
\hline 19 & $\begin{array}{l}\text { Pelvic fracture, splenic rupture, right femoral neck } \\
\text { fracture, and fracture of left tibial plateau }\end{array}$ & 14 May 2008 & $\sqrt{ }$ & 470 & ++ & 6 \\
\hline 20 & $\begin{array}{l}\text { Brain trauma, fracture of lower shaft of femur, and } \\
\text { right fibula fracture }\end{array}$ & 14 May 2008 & $\sqrt{ }$ & 540 & ++ & 3.5 \\
\hline 21 & $\begin{array}{l}\text { Pelvic fracture, left femoral neck fracture, and right } \\
\text { fibula fracture }\end{array}$ & 14 May 2008 & $\sqrt{ }$ & 390 & +++ & 3 \\
\hline 22 & $\begin{array}{l}\text { Chest trauma, fracture of shaft of left humerus, and } \\
\text { right ulna fracture }\end{array}$ & 14 May 2008 & $\sqrt{ }$ & 730 & ++ & 5 \\
\hline
\end{tabular}


Table 1 (Continued)

\begin{tabular}{|c|c|c|c|c|c|}
\hline 23 & $\begin{array}{l}\text { Brain trauma, compression fracture of lumber } \\
\text { vertebral body, pelvic fracture, and right tibiofibula } \\
\text { fracture }\end{array}$ & 14 May $2008 \sqrt{ }$ & 70 & ++++ & 18 \\
\hline 24 & $\begin{array}{l}\text { Chest trauma, fracture of shaft of left humerus, and } \\
\text { right radius fracture }\end{array}$ & 14 May 2008 & 830 & ++ & 9.5 \\
\hline 25 & Right tibiofibula fracture & 14 May $2008 \sqrt{ }$ & 460 & +++ & 11 \\
\hline 26 & $\begin{array}{l}\text { Pelvic fracture, compression fracture of } \\
\text { choracic } 12 / \text { lumber } 1 \text { vertabral body, splenic } \\
\text { rupture, retroperitoneal hematoma, fracture of shaft } \\
\text { of right femur, and left tibiofibula fracture }\end{array}$ & 15 May $2008 \sqrt{ }$ & 60 & ++++ & 16 \\
\hline 27 & $\begin{array}{l}\text { Chest trauma, fracture of shaft of right femerus, } \\
\text { and left ulna fracture }\end{array}$ & 15 May 2008 & 850 & ++ & 6 \\
\hline 28 & Chest trauma and fracture of shaft left femerus & 15 May 2008 & 780 & ++ & 13 \\
\hline 29 & $\begin{array}{l}\text { Pelvic fracture, splenic rupture, and fracture of right } \\
\text { femerus shaft }\end{array}$ & 16 May $2008 \sqrt{ }$ & 70 & ++++ & 32 \\
\hline 30 & $\begin{array}{l}\text { Brain trauma, pelvic fracture, left inferior femur } \\
\text { fracture, and right fibula fracture }\end{array}$ & 16 May $2008 \sqrt{ }$ & 490 & ++ & 12 \\
\hline 31 & Fracture of right femur shaft & 17 May 2008 & 670 & ++ & 9 \\
\hline 32 & $\begin{array}{l}\text { Chest trauma, fracture of shaft of left femur, and } \\
\text { right olecroanon fracture }\end{array}$ & 19 May $2008 \sqrt{ }$ & 50 & ++++ & 121 \\
\hline
\end{tabular}

The criteria of crush syndrome in our group were: over one hour pressing of the body parts; involvement of large amount of muscular tissue; development of pallor, clamminess, cold skin, pulselessness, or shock; and the development of manifestations of acute renal failure which are: oliguria less than $400 \mathrm{ml} / 24$ hours, BUN increase more than $40 \mathrm{mg} / \mathrm{dl}$, creatinine increase more than $2 \mathrm{mg} / \mathrm{dl}$, serum potassium increase more than $6 \mathrm{mmol} / \mathrm{l}$, serum phosphorus increase more than 6 $\mathrm{mg} / \mathrm{dl}$ or serum calcium decrease less than $8 \mathrm{mg} / \mathrm{dl}$. Upon admission, the patients were immediately given interventions such as anti-shock treatment, alkalifying urine, correcting water and electrolyte disturbances, diuresis, dehydration, and anti-infection treatments. Twenty-seven patients received antishock treatment, 25 received urine alkalization, 19 received hemodialysis, 15 received fasciotomy, and 5 received amputation due to severe infection. All patients received broad-spectrum antibiotics to control infection and tetanus antitoxin.

Acutely increased interaponeurosis pressure in victims of crush injury can lead to severe muscle necrosis, which requires surgical intervention. Prompt fasciotomy can save lives and prevent the development of dangerous complications after crush syndrome. Indications for fasciotomy included increased turgid of pressed limbs with high tension or/and local ecchymosis, blister in the skin, symptom of 5 "P" (Pain, Pallor, Paralysis, Parathesias, and Pulselessness), persistent urine myoglobin, or interaponeurosis pressure higher than 40 $\mathrm{mmHg}$. Hemodialysis is the first choice for crush syndrome patients complicated with acute renal failure and hyperpotassemia. Indications for hemodialysis included serum creatinine level above $8 \mathrm{mg} / \mathrm{dl}$, BUN above $100 \mathrm{mg} / \mathrm{dl}$, serum potassium above $7 \mathrm{mmol} / \mathrm{l}$, serum bicarbonate below $10 \mathrm{mEq} /$ I, or/and clinical symptoms of ARF, such as edema, hypertension, heart failure, nausea, and vomiting.

\section{Monitoring of dangerous complications in patients with crush injury}

The most important symptom of crush syndrome is acute kidney injury. ARF is defined when a patient with crush injury has one of the following symptoms: oliguria (urine output $<400$ $\mathrm{ml} / 24$ hours), increases of BUN ( $>40 \mathrm{mg} / \mathrm{dl}$ ), serum creatinine $(>2 \mathrm{mg} / \mathrm{dl})$, uric acid ( $>8 \mathrm{mg} / \mathrm{dl})$, potassium $(>6 \mathrm{mmol} /$ I), phosphorus $(>8 \mathrm{mg} / \mathrm{dl})$, or decrease of serum calcium $(<8$ $\mathrm{mg} / \mathrm{dl})[12,13]$. We observed the incidence rates of traumatic shock, ARF, acute pulmonary edema (APE), stress ulcer (SU), and multiple-organ dysfunction syndrome (MODS) as well as the vital signs of the patient. Besides, we also closely monitored the changes of urine output, serum BUN, serum creatinine, serum uric acid, urine protein, and serum CK, ALT and $\mathrm{LDH}$. The decrease in amputation rate and morbidity rate were also used to evaluate the outcomes of patients.

\section{Statistical analysis}

All the data were expressed as mean \pm standard deviation. Paired t-tests were used when the difference of pre- and posttreatment was in a normal distribution. When the variables did 
not have a normal distribution and ranked data, the Wilcoxon signed rank sum test was utilized. All data were evaluated using a Microsoft Excel 97 spreadsheet (Microsoft Excel, Seattle, Washington, USA) and SAS9.12 statistical software. Statistical significance was assigned at $P<0.05$.

\section{Results \\ Improvement of laboratory parameters of patients after intervention}

Two weeks after comprehensive treatment, the serum parameters of most patients were greatly improved (Table 2). All the six cases of death had a serum CK level of more than $5000 \mathrm{u} /$ $\mathrm{L}$; two cases of death had a serum potassium level higher than $6.0 \mathrm{mmol} / \mathrm{L}$, which could not be corrected. In the 26 surviving cases the CK value rapidly decreased to below $1000 \mathrm{u} / \mathrm{L}$.

Treatment of complications of patients with crush injury Of the 32 patients, $18(56.25 \%)$ had traumatic shock, 11 had ARF (34.38\%), 6 had APE (18.75\%), 2 had SU (6.25\%) and 4 had MODS (12.5\%); all 4 patients that developed MODS died and the other 26 had improved symptoms. After pertinent treatments, the surviving patients had relieved swelling and distension, and recovered from dysesthesia and anesthesia. Sixteen patients had their dyscinesia symptoms improved and 15 had normal urine output.

A particular case in our group worth further discussion was a 15-year-old girl who had tibial and fibula fracture of her right leg during the earthquake. On admission she had a swelled right leg with fracture blisters on the skin and a decreased pulse of the dorsalis pedis artery. The doctor who first performed the emergent operation for her fractures neglected the risk of crush syndrome. On the next day after fracture fixation, the girl had an acutely reduced urine output (below $100 \mathrm{ml} / 24$ hours) combined with tachypnea, orthopnea, and expectoration of bloody sputum. Auscultation showed moist rales in bilateral lungs. The heart rate (HR) was 140 to 160 beat/min and respiratory rate (RR) was 35 to 46 breaths/min. Pulse oxygen saturation was only $60 \%$. Therefore, she was transferred to our ICU and was diagnosed with crush syndrome accompanied by APE. She was immediately subjected to ventilation by mask oxygen, intravenous injection of cardiotonic, diuretics and hemofiltration. Gradually, the HR and RR of patients decreased and the pulse oxygen saturation was improved.

\section{Comprehensive treatment of crush syndrome and the outcome of patients}

Seventeen (53.13\%) of the 32 patients met the diagnosis criterion of crush syndrome. Eighteen (56.25\%) patients had traumatic shock, $11(34.38 \%)$ had ARF, 6 had acute heart failure, $2(6.25 \%)$ had stress ulcer, and $4(12.5 \%)$ had MODS. Six $(18.75 \%)$ patients died in our group, one due to severe capillary leak syndrome, one due to uncontrolled infection after amputation, and four due to MODS. Five (15.63\%) patients received amputation due to severe infection of the involved limbs. The 26 surviving patients were alive and well three months later. The major treatment of crush syndrome included anti-shock treatment, surgical intervention and hemodialysis. In total 18 patients received prompt anti-shock treatment and 12 patients were successfully resuscitated. Prompt surgical interventions were given to 15 of the 19 patients who had the indications for fasciotomy; the other four patients did not receive fasciotomy due to severe infection of the wounds. Seventy-two hours later, the limb swelling was aggravated in one of the four patients who did not received fasciotomy initially, and several blisters appeared on the local skin, accompanied by local ecchymosis and decreased artery pulse, indicating increased intramuscular pressure, and fasciotomy was performed finally, but the patient died of MODS. Eleven (34.38\%) patients with proper indications received hemodialyses: all of them had different degrees of ARF symptoms, 5 had hyperpotassemia, 7 had anuria, and 4 had combined hyperpotassemia, anuria, and elevated creatinine. The mean urine output of the patient rose from $174.5 \pm 82.7 \mathrm{ml}$ to $954.6 \pm 132.5 \mathrm{ml}$ after

Table 2

Improvement of laboratory parameters after treatment in 32 patients with crush injury

\begin{tabular}{llll}
\hline & Pre-intervention & Post-intervention & $P$ \\
\hline LDH (u/L) & $5725 \pm 1859$ & $736 \pm 1182$ & 0.000 \\
\hline ALT (u/L) & $258 \pm 164$ & $69 \pm 25$ & 0.000 \\
\hline Potassium (mmol/L) & $5.4 \pm 2.4$ & $3.8 \pm 1.2$ & 0.000 \\
\hline Creatinine (umol/L) & $794 \pm 85$ & $261 \pm 67$ & 0.000 \\
\hline CK (u/L) & $4697 \pm 359$ & $2281 \pm 263$ & 0.000 \\
\hline BUN (mmol/L) & $32.6 \pm 12.8$ & $12.7 \pm 8.7$ & 0.000 \\
\hline Severity of urine protein & ++ to ++++ & \pm to + & 0.000 \\
\hline
\end{tabular}

$\mathrm{ALT}=$ alanine aminotransferase $; \mathrm{BUN}=$ blood urea nitrogen; $\mathrm{CK}=$ creatine kinase $\mathrm{LDH}=$ lactate dehydrogenase. 
treatment $(P<0.05)$, and the urine output of 15 patients was restored to normal levels.

\section{Discussion}

In this paper we reported the treatment of 32 patients with crush injury in a front-line tent ICU, which was established near the epicenter of the Wenchuan earthquake and was equipped with facilities rescued from the collapsing buildings of a local hospital. Close monitoring and prompt intervention have helped to save the lives of the 26 patients. The tent ICU is of great significance in saving the lives of patients with crush injury following a major disaster. More attention should be given to setting up a well-designed front-line ICU for major disasters.

\section{Advantages of front-line ICU after an earthquake}

A front-line ICU is very important for treatming crush injury patients after disasters such as an earthquake, because it is equipped with advanced facilities and first aid materials needed for critical conditions. A front-line ICU, such as ours, can be located on the site of the disaster, giving treatment in a timely manner [24-26]. It is reported that most victims of disasters and wars died on the spot where they were injured. For example, in a war $40 \%$ of the patients died immediately after injury, 25\% died 5 minutes after injury, $15 \%$ died 5 to 30 minutes after injury, and $20 \%$ died 30 minutes after injury; it is indicated that timely treatment of these patients is vital. A front-line ICU can provide this timely treatment, relieve the symptoms of patients, improve their biochemical parameters, and reduce crush syndrome complications, allowing for surgical intervention of the patients. After a major disaster such as Wenchuan earthquake, there will be a large number of patients with crush injury. When compartment syndrome, ARF and/or other severe complications occur, the patients need to be sent to the ICU immediately for closer monitoring. A tent ICU near the epicenter can not only provide timely treatment to the victims, but also avoid the risks of aggravation of patients' condition during the evacuation $[27,28]$.

\section{Close monitoring, early diagnosis and treatment of crush syndrome}

There are a large number of crush injury patients following a major earthquake, and early diagnosis and close monitoring can lower the incidence of crush syndrome. In addition to monitoring the vital signs, more attention should be paid to observing the patient's blood pressure and changes of urine in order to make an early diagnosis of crush syndrome. Observation of the color and volume of urine and the urine protein is also a key step to prevent the transition from crush injury to crush syndrome. Furthermore, monitoring and correcting hypotension can prevent ARF in patients with crush syndrome. In our ICU, only limited biochemical parameters were obtainable; however, close monitoring of the above-mentioned parameters helped us to make early diagnosis and treatment assessments. Due to the limited parameters we could obtain, observation of urine output served as an important parameter for diagnosis of patients and for predication of prognosis. The serum parameter changes caused by muscle necrosis are very important in the diagnosis of crush syndrome. Unfortunately, some important parameters could not be obtained in our ICU due to limited equipment. Sophisticated biochemical instruments are essential for a front-line ICU.

Reportedly, 7 out of 10 patients with crush injury after a catastrophic earthquake developed crush syndrome, and $10 \%$ of the total casualty number was due to crush syndrome. Therefore, prevention and management of crush syndrome are critical to lower the mortality rate. The survival rate of our group is $81.25 \%$, greatly higher than that reported previously [29-31].

The major differences of treatments between crush injury and other types of traumas include that patients with crush injury need early and prompt expansion of blood volume to guarantee renal perfusion, correction of acidosis and relief of limb swelling. Most patients with crush injury are in a state of hypotension and need intravenous administration of a large volume of fluids, including artificial plasma, 5\% glucose, $\mathrm{NaHCO} 3$, aescigenin, and human serum albumin. Colloid should be used to elevate the osmotic pressure and relieve inter-aponeurosis edema; diuretics such as indapamide should be used when circulation is stable. Although mannitol is effective in decreasing inter-aponeurosis pressure, it was not used in our cohort to avoid aggravation of renal function; instead, aescigenin, human serum albumin, and indapamide were used in our patients to relieve swelling of the injured limbs.

\section{Surgical intervention and post-operation monitoring of patients with crush syndrome}

Duman and colleagues believed that prompt fasciotomy in earthquake victims are both life-saving and can prevent some of the severe and dangerous complications of crush syndrome [3]. In fact, not only can close fractures lead to compartment syndrome, but open fractures can also result in it; radical debridement should be performed for open fracture and repeated debridement is needed when necessary. Fasciotomy and expansion of wounds should be performed to remove the necrotic tissues to ensure unobstructed drainage. The aim of fasciotomy is to prevent muscle necrosis, compartment syndrome and the need for amputation. Those who took a negative altitude toward fasciotomy in earthquake victims thought that resection of a large volume of muscle together with the surrounding tissues would inevitably cause loss of fluid and increase the chance of infection. Infection secondary to fasciotomy and primary trauma of earthquake victims have always been grave challenges in the clinic. Ekrem [32] reported that the incidence of severe infection was as high as $37.3 \%$ in patients with crush injury. Therefore, in a front-line ICU, the surgical wounds should be closely observed and anti-infection measures should be promptly taken when necessary. In our group, five patients have to receive amputations because of 
aggravated distension of compressed extremities, deterioration of ecchymosis and blister, local skin becoming purple/ black in color, hyperpyrexia and acute increase of leucocytes. Postoperatively, the patients were closely monitored and the incisions were observed. Only one patient of the five died of uncontrollable infection. We believe that surgical intervention of earthquake victims should be considered for earthquake victims when the correct indications are strictly followed.

\section{Close monitoring of severe complications of crush syndrome}

The common complications of crush syndrome include traumatic shock, ARF, acute heart failure, SU, and MODS; early diagnosis and intervention are vital to the survival of patients. In our group, the incidence rates of the aforementioned complications were similar to those reported previously [33-35].

In our front-line tent ICU, energetic anti-shock measures were taken for 18 patients who had traumatic shock to avoid the development of crush syndrome, because many severe fatal complications develop due to long periods of shock. SU is a common manifestation at the final stage of patients in shock and often develops under stress. The incidence rate of SU was reportedly about $4 \%$ to $10 \%$ in trauma patients $[36,37]$. Two of our patients suffered from SU. The result indicated that it was necessary to adopt early active mental intervention to relieve the mental stress. The most severe complication of crush injury is MODS. Four of our patients developed MODS and all died. So it is especially important to monitor the functions of major organs to prevent MODS in the front-line ICU. Experience with the 15-year-old girl indicates that APE can also be the first clinical manifestation of crush syndrome; and the necrosis of leg muscle as well as that of the huckle (the part of the leg close to groin) can lead to crush syndrome [3840].

Eleven of our 32 patients had ARF, a dangerous manifestation of crush syndrome. Hemodialysis is the best choice of treatment for ARF and prevention of crush syndrome. It is reported that hemodialysis can keep the incidence of internal environment disorder and other complications to a minimum. The urine output recovered to normal levels in 11 patients who received hemodialysis. Our ICU only had one hemodialyzer, so patients could not receive continuous hemodialysis and four of our patients developed MODS and died. Advanced portable biochemical analyzer in the front-line ICU allows for close monitor of patients with crush injury, and a blood dialyzer can give prompt, effective treatment to patients who's condition is complicated with ARF [41,42]. When rescuing after a disaster such as the Whenchuan Earthquake, more portable hemodialyzers should be deployed to provide prompt treatment of patients with crush syndrome.

\section{Conclusions}

Severe crush injuries and their life-threatening complications such as crush syndrome are common after a major earthquake like the one that occurred in Wenchuan. The establishment of a front-line ICU close to the epicenter of earthquake allows for a prompt on-spot monitoring and rescue of critical patients suffering from severe traumatic injury, which can decrease the mortality rate and complications in patients with severe crush injury, avoid amputation, and should be encouraged.

\section{Key messages}

- Severe crush injuries and their life-threatening complications such as crush syndrome are common after a major earthquake like the one that occurred in Wenchuan.

- Six (18.75\%) patients died in our group, one due to severe capillary leak syndrome, one due to uncontrolled infection after amputation, and four due to MODS. Five (15.63\%) patients received amputation due to severe infection of the involved limbs.

- The establishment of a front-line ICU close to the epicenter of the earthquake allows for prompt on-the-spot monitoring and rescue of critical patients suffering from severe traumatic injury, and should be encouraged and studied further.

- In addition to the monitoring of the vital signs, more attention should be paid to observation of the blood pressure and changes of urine to make an early diagnosis of crush syndrome.

- We believe that surgical intervention of earthquake victims should be considered for earthquake victims when the correct indications are strictly followed.

\section{Competing interests}

The authors declare that they have no competing interests.

\section{Authors' contributions}

WL was responsible for data collection, analysis and writing the manuscript. JQ, XL, and $\mathrm{QZ}$ participated in data collection and analysis. LW and DC participated in the data collection and revising the manuscript. $Z \mathrm{~L}$ was responsible for the overall design of the manuscript. All the authors have read and approved the submission.

\section{Acknowledgements}

Written consent for publication was obtained from the patients or their relatives. The authors thank Danghui Yu from the Second Military Medical University for polishing the English language of the manuscript.

\section{References}

1. Beetham R: Biochemical investigation of suspected rhabdomyolysis. Ann Clin Biochem 2000, 37:581-587.

2. Tahmasebi MN, Kiani K, Mazlouman SJ, Taheri A, Kamrani RS, Panjavi B, Harandi BA: Musculoskeletal injuries associated with earthquake: A report of injuries of Iran's December 26, 2003 
Bam earthquake casualties managed in tertiary referral centers. Injury 2005, 36:27-32.

3. Duman $\mathrm{H}$, Kulahci $\mathrm{Y}$, Sengezer M: Fasciotomy in crush injury resulting from prolonged pressure in an earthquake in Turkey. Emerg Med J 2003, 20:251-252.

4. Anna T, Jan EM, Olav R: Multifocal orterial haemorrhage in a partially stable pelvic fracture after a crush injury: a case report. Arch Orthop Trauma Surg 2006, 126:113-117.

5. Necmi K, Hasan FK, Recep D, Altaca G: Crush injury in two earthquake disasters within a 3-month period. European Journal of Trauma 2003, 29:42-45.

6. Serdar HI, Harika A, Halil T, Cevdet O, Suat HA, Kerem O, Mehmet $\mathrm{B}$, Cihangir T, Tolga ED: Analysis of $\mathbf{3 3}$ pediatric trauma victims in the 1999 Marmara, Turkey earthquake. J Pediatr Surg 2001, 36:368-372.

7. Shackford SR, Rich NH: Peripheral vascular injury. 4th edition. Edited by: Mattox KL, Feliciano DV, Moore EE. Trauma: New York; McGraw-Hill; 2000:1011-1046.

8. Gorgu M, Adanali G, Tuncel A, Senen D, Erdogan B: Airbags and wearing seat belts prevent cut-crush injuries or reduce severity of injury in low-speed traffic accidents. Eur J Plast Surg 2002, 25:215-218

9. Michael JS, Michael EM: Reliability of vacuum phenomenon in the sacroiliac joint as a sign of traumatic injury. Emergency Radiology 2002, 9:100-102.

10. Gulcin K, Raymond V, Serhan T, Haken A, Mehmet K, Cetin O: Acute renal failure due to crush syndrome during Marmara earthquake. Am J Kidney Diseases 2002, 40:682-689.

11. Reintam A, Parm P, Kitus R, Kern H, Starkopf J: Primary and secondary intra-abdominal hypertension-different impact on ICU outcome. Intensive Care Med 2008, 34:1624-1631.

12. Plotz FB, Bouma AB, vanWijk JA, Kneyber MC Bokenkamp A: Pediatric acute kidney injury in the ICU: an independent evaluation of pRIFLE criteria. Intensive Care Med 2008, 34:1713-1717.

13. Yeolekar ME, Mehta S: ICU care in India--status and challenges. J Assoc Physicians India 2008, 56:221-222.

14. Gortzis LG, Sakellaropoulos F, llias I, Stamoulis K, Dimopoulou I: Predicting ICU survival: a meta-level approach. BMC Health Serv Res 2008, 8:157.

15. Beloucif S: How to fight against refusals of admission to ICU of elderly patients? Ann Fr Anesth Reanim 2008, 27:470-471.

16. Rabbat $A$, Chaoui $D$, Lefebvre $A$, Roche $N$, Legrand $O$, Lorut $C$, Rio $B$, Marie JP, Huchon G: Is BAL useful in patients with acute myeloid leukemia admitted in ICU for severe respiratory complications? Leukemia 2008, 22:1361-1367.

17. Acharya SP, Pradhan B, Marhatta MN: Application of "the Sequential Organ Failure Assessment (SOFA) score" in predicting outcome in ICU patients with SIRS. KUMJ 2007, 5:475-483.

18. Mahoney EJ, Biffl WL, Cioffi WG: Mass-casualty incidents: how does an ICU prepare? J Intensive Care Med 2008, 23:219-235.

19. Mellert F, Lindner P, Schiller W, Gersing E, Heinze I, Kreuz J, Welz A, Preusse CJ: Therapeutic optimization of atrioventricular delay in cardiosurgical ICU patients by noninvasive cardiac output measurements versus pulse contour analysis. Thorac Cardiovasc Surg 2008, 56:269-273.

20. Demirkiran O, Dikmen Y, Utku Y, Urkmez S: Crush syndrome patients after the Marmara earthquake. Emerg Med J 2003, 20:247-250.

21. Honore PM, Joannes BO, Boer WJG, Gressens B: Acute kidney injury in the ICU: time has come for an early biomarker kit! Acta Clin Belg Supp/ 2007, 2:318-321.

22. Ali IG, Huseyin C, Ayhan D, Goksel O, Ercan K, Huseyin S, Izzettin G, Mustafa D, Oktay B, Mustafa AY, Mehmet SS: Early and vigorous fluid resuscitation prevents acute renal failure in the crush victims of catastrophic earthquakes. J Am Soc Nephrol 2004, 15:1862-1867.

23. Mehmet SS, Raymond V, Norbert L: Management of crushrelated injuries after disasters. $N$ Engl J Med 2006, 354:1052-1063.

24. Rocco M, Carbone I, Morelli A, Bertoletti L, Rossi S, Vitale M, Montini L, Passariello R, Pietropaoli P: Diagnostic accuracy of bedside ultrasonography in the ICU: feasibility of detecting pulmonary effusion and lung contusion in patients on respiratory support after severe blunt thoracic trauma. Acta Anaesthesiol Scand 2008, 52:776-784.
25. Mahoney EJ, Biffl WL, Cioffi WG: Mass-casualty incidents: how does an ICU prepare? J Intensive Care Med 2008, 23:219-235.

26. Velmahos GC, Demetriades D, Ghilardi M, Rhee P, Petrone P, Chan LS: Life support for trauma and transport: a mobile ICU for safe in-hospital transport of critically injured patients. $J \mathrm{Am}$ Coll Surg 2004, 199:62-68.

27. Alvarez GM, Cambronero GJA, Nevado LE, Trascasa MM, Connor ME, Sanchez GM: Effect of the availability of a medicalized mobile ICU (MMICU) on the hospital admissions after an outof-hospital cardiorespiratory arrest. Rev Clin Esp 2003, 203:517-520.

28. Yue MX, Zou DW, Zhang J, Liu ZG, Cui SJ, Fang WW, Zhou XF, Gao TS, Hua N: Establishment of a mobile intensive care unit. Zhongguo Wei Zhong Bing Ji Jiu Yi Xue 2004, 16:589-591.

29. Kopp JB, Ball LK, Cohen A, Kenney RJ, Lempert KD, Miller PD, Muntner $\mathrm{P}$, Qureshi N, Yelton SA: Kidney patient care in disasters: lessons from the hurricanes and earthquake of 2005. Clin J Am Soc Nephrol 2007, 2:814-824.

30. van der Tol A, Hussain A, Sever MS, Claus S, Van Biesen W, Hoste E, Khan S, Vanholder R: Impact of local circumstances on outcome of renal casualties in major disasters. Nephrol Dial Transplant 2008, 8:1-6.

31. Vanholder Raymond: Intervention of the renal disaster relief task force (RDRTF) in the Kashmir earthquake. Nephrol Dial Transplant 2006, 21:40.

32. Erek E, Sever MS, Serdengeçti K, Vanholder R, Akoğlu E, Yavuz M, Ergin $\mathrm{H}$, Tekçe M, Duman N, Lamiere N, et al.: An overview of morbidity and mortality in patients with acute renal failure due to crush syndrome: the Marmara earthquake experience. Nephrol Dial Transplant 2002, 17:33-40.

33. Sakka SG, Klein M, Eeinhart K, Meier-Hellmann A: Prognostic value of extravascular lung water in critically ill patients. Chest 2002, 122:2080-2086.

34. Kario K, Matsuo T, Shimada K, Pickering TG: Factors associated with the occurrence and magnitude of earthquake-induced increases in blood pressure. Am J Med 2001, 111:379-384.

35. Levy MM, Fink MP, Marshall JC, Abraham E, Angus D, Cook D, Cohen J, Opal SM, Vincent JL, Ramsay G: 2001 SCCM/ESICM/ ACCP/ATS/SIS International sepsis definitions conference. Crit Care Med 2003, 31:1250-1256.

36. Meybohm P, Cavus E, Bein B, Steinfath M, Weber B, Hamann C Scholz J, Dorges V: a randomized controlled trim with either norepinephrine or vasopressin during severe hemorrhage. Trauma 2007, 62:640-646

37. Xingyi $Y$, Wenfang L, Ming $Y$, Dechang C, Liang Z, Zhaofen L: Clinical analysis of 176 patients suffered from upper gastrointestinal bleeding in intensive care unit. Chinese Journal of Digest 2004, 24:179-180.

38. Deborah LC, Monte SW, White DJ, Horton JW, Brett PG: Tumor necrosis factor- $\alpha$-induced caspase activation mediates endotoxin - related cardiac dysfunction. Crit Care Med 2005, 33:1021-1028.

39. Werman HA, Jaynes C, Blevins G: Impact of a triage tool on air versus ground transport of cardiac patients to a tertiary center. Air Med J 2004, 23:40-47.

40. Kreimeier U, Prueckner S: Small volume resuscitation from hemorrhagic shock by hypertonic saline dextran conceptional basis and historical background. Eur Surg Res 2002, 34:138-144.

41. Hachimi Idrissi S, Yang X, Nguyen DN, Huyghens L: Combination of therapeutic mild hypothermia and delayed fluid resuscitation improved survival after uncontrolled haemorrhagic shock in mechanically ventilated rats. Resuscitation 2004, 62:303-310

42. Katzenelson $R$, Perel A, Berkenstadt $H$, Preisman $S$, Kogan $S$, Sternik L, Segal E: Accuracy of transpulmonary therm odilution versus gravimetric measurement of extravascular lung water. Crit Care Med 2004, 32:1550-1554. 